\title{
Limitation of Activities of Daily Living and Quality of Life Based on COPD Combined Classification
}

\author{
Marina S Barusso PT, Júlia Gianjoppe-Santos PT MSc, Renata P Basso-Vanelli PT PhD, \\ Eloisa MG Regueiro PT PhD, Jéssica C Panin, and Valéria A Pires Di Lorenzo PT PhD
}

\begin{abstract}
BACKGROUND: The Global Initiative for Chronic Obstructive Lung Disease (GOLD) 2011 update recommends that the management and treatment of COPD be made to combine the impact of disease and future risk of exacerbation. These patients have worsening quality of life and limitation of activities of daily living (ADLs), which can be manifested as a decrease in $\mathrm{S}_{\mathrm{pO}_{2}}$ and progressive dyspnea. The aim of this study was to determine whether the COPD combined classification proposed by GOLD 2011 is able to differentiate patients with ADL limitation, such as oxygen desaturation or dyspnea, and impaired quality of life. METHODS: This was an observational, cross-sectional study. Forty-four subjects were categorized in 4 GOLD groups (A-D). The mean age was $69 \pm 8.8 \mathrm{y}$, with $\mathrm{FEV}_{1}$ of $1.33 \pm 0.53 \mathrm{~L}(49 \pm 15.7 \%$ of predicted $)$. The Modified Medical Research Council dyspnea and London Chest Activity of Daily Living (LCADL) scales and the St George Respiratory Questionnaire (SGRQ) were applied. The 6-min walk test and ADL simulation in an appropriate laboratory were also conducted. RESULTS: There was no association between the COPD combined evaluation groups and the presence of oxygen desaturation and dyspnea (chi-square test), although a higher prevalence of oxygen desaturation was noticed in group D subjects. With regard to dyspnea, there were subjects with dyspnea in all groups when ADLs were performed. No correlation between dyspnea and oxygen desaturation variation was found. Group B and D subjects showed higher ADL dyspnea (total LCADL scores of $28 \%$ and 30\%) compared with group A subjects. Group D subjects showed poorer quality of life (total SGRQ score of $49.3 \%$ ) compared with less symptomatic groups. CONCLUSIONS: The COPD combined classification was not efficient in determining oxygen desaturation and dyspnea while subjects were performing ADLs. The subjects in the symptomatic groups with increased risk of exacerbation showed poorer quality of life and higher dyspnea levels. (ClinicalTrials.gov registration NCT01977469) Key words: COPD classification; oxygen desaturation; dyspnea; daily living activities; quality of life. [Respir Care 2015;60(3):388-398. () 2015 Daedalus Enterprises]
\end{abstract}

\section{Introduction}

COPD is a chronic, preventable, and treatable inflammatory disease characterized by progressive and persistent

\footnotetext{
Ms Barusso, Ms Gianjoppe-Santos, Dr Basso-Vanelli, Ms Panin, and Dr Di Lorenzo are affiliated with the Laboratory of Spirometry and Respiratory Physiotherapy, Physiotherapy Department, Universidade Federal de São Carlos, São Carlos, São Paulo, Brazil. Dr Regueiro is affiliated with the Centro Universitário UNIFAFIBE, Bebedouro, and the Centro Universitário Claretiano, Batatais, São Paulo, Brazil.
}

This study was supported by a scholarship from the Conselho Nacional de Pesquisa e Desenvolvimento Científico e Tecnológico. The authors have disclosed no conflicts of interest. air-flow obstruction. Its severity is influenced by comorbidities and history of exacerbations. Although diagnosis is based on post-bronchodilator spirometry, the severity classification is based on percent-of-predicted $\mathrm{FEV}_{1} \cdot{ }^{1}$

According to the Global Initiative for Chronic Obstructive Lung Disease (GOLD) classification, the degree of air-flow limitation assessed in an isolated way is a poor

\footnotetext{
Correspondence: Valéria A Pires Di Lorenzo PT PhD, Universidade Federal de São Carlos, Rodovia Washington Luís, km 235, Monjolinho, CEP 13565-905, São Carlos, São Paulo, Brazil. E-mail: vallorenzo@ufscar.br.
}

DOI: $10.4187 /$ respcare. 03202 


\section{Limitation of Activities of Daily Living ANd COPD}

predictor of other COPD features. ${ }^{2}$ In the 2011 update, this limitation was recognized, and GOLD recommended that the management and treatment of COPD must match the impact of the disease, which is determined by assessment of symptoms and limitations of activities of daily living (ADLs), and the future risk of exacerbation, which is determined by air-flow limitation and history of exacerbations. ${ }^{3}$ Thus, subjects were categorized and treated according to 4 groups: A, low risk, few symptoms; B, low risk, many symptoms; $\mathrm{C}$, high risk, few symptoms; and D, high risk, many symptoms. ${ }^{1}$

With worsening of the disease, there is a progressive decrease in the ability to perform ADLs, ${ }^{4}$ with a decrease in peripheral $\mathrm{S}_{\mathrm{pO}_{2}}$, progressive dyspnea, and exercise intolerance. Oxygen desaturation may occur in patients with normal $\mathrm{S}_{\mathrm{pO}_{2}}$ at rest and in those who are hypoxemic at rest. Oxygen desaturation may occur during activities such as walking, washing, and eating, ${ }^{5}$ thus limiting these activities, and happens simultaneously with the onset of dyspnea. ${ }^{6}$

Dyspnea is one of the most important and debilitating symptoms in subjects with COPD and certainly the trigger point to the vicious cycle of physical inactivity. ${ }^{7}$ Several instruments have been developed for the assessment of dyspnea in ADLs. The Modified Medical Research Council (MMRC) dyspnea scale ${ }^{8}$ and the London Chest Activity of Daily Living (LCADL) scale ${ }^{9}$ assess dyspnea based on patients' perceptions of past events, and the Borg scale assesses dyspnea reported during exercise or ADLs.

Dyspnea is the most frequent complaint while patients are performing ADLs, ${ }^{10}$ and it limits exercise performance as well as ability to perform basic ADLs, such as self-care and mobility. These are simple activities, essential to a patient's independence, as they allow patients to carry out activities at home. ${ }^{11}$

Instrumental ADLs also undergo changes due to breathlessness, as these are more complex activities, such as preparing meals, house maintenance, and all other leisure activities. As a consequence of increased dyspnea, patients adapt themselves by reducing the amount of all ADLs performed, with a consequent reduction in quality of life, which is associated with actual limitations in performing ADLs. ${ }^{12}$

Nevertheless, there is no evidence in the literature confirming that patients belonging to high-risk groups (GOLD $\mathrm{C}$ and $\mathrm{D}$ ) show increased ADL limitation and worse quality of life. In this context, the primary aim of this study was to investigate whether the COPD combined classification proposed by GOLD 2011 was able to discriminate subjects with ADL limitations, such as oxygen desaturation and dyspnea, and impaired quality of life. A secondary aim was to compare the quality of life, dyspnea, and oxygen desaturation during ADLs among groups stratified by GOLD 2011 classification. We hypothesized that there

\section{QUICK LOOK}

\section{Current knowledge}

COPD is a chronic inflammatory disease characterized by progressive and persistent air-flow obstruction. COPD severity is influenced by the presence of comorbidities and frequency of exacerbations. The severity classification of COPD is based on the percent-of-predicted $\mathrm{FEV}_{1}$.

\section{What this paper contributes to our knowledge}

A COPD combined classification system was not efficient in determining which subjects suffered oxygen desaturation and dyspnea while performing activities of daily living. The subjects in the symptomatic groups had an increased risk of exacerbation and demonstrated a diminished quality of life and higher dyspnea level.

would be an association among the subject's group classification according to the GOLD COPD combined evaluation and ADL limitations, as well as an association between the subject's GOLD classification and reduced quality of life.

\section{Methods}

\section{Study Design and Subjects}

This observational, cross-sectional study was conducted in the Laboratory of Spirometry and Respiratory Physiotherapy of the Universidade Federal de São Carlos, in São Paulo, Brazil, from December 2012 to September 2013.

Inclusion criteria were: subjects of both genders with COPD,${ }^{1}>50$ y of age, clinically stable, absence of infection, no exacerbation, and no change in medication for at least 2 months before inclusion in the study; dependent or not on home oxygen therapy; and absence of severe heart disease and of any other pathology that did not allow the performance of the proposed tests. Exclusion criteria were: systemic hypertension and uncompleted evaluation proposals. All included subjects signed a consent form approved by the human ethics committee of the university (decision 243/2012). After the assessment, all subjects were referred for pulmonary rehabilitation.

\section{Study Subjects}

Subjects were categorized into 4 groups (A-D) according to GOLD 2011 recommendations $^{3}$ using the MMRC scale, $\mathrm{FEV}_{1}$, and history of exacerbations in the previous year before the study. GOLD indicated the need to use 


\section{Limitation of Activities of Daily Living ANd COPD}

only one scale to assess symptoms, so the MMRC scale was chosen. The standard choice was based on the higher score in $\mathrm{FEV}_{1}$ and exacerbation history. Exacerbation was defined as any acute event characterized by worsening of respiratory symptoms that exceeded the normal daily variation and that caused the need for changes in medication ${ }^{1}$ and/or use of health-care resources. ${ }^{13}$

\section{Procedures}

Subjects were assessed by a trained physiotherapist on non-consecutive days with a 48-d interval between assessments. In the first assessment, the subjects' history, anthropometric data, and the MMRC scale ${ }^{14}$ were collected. In the second assessment, two 6-min walk tests were performed, ${ }^{15}$ and the St George Respiratory Questionnaire (SGRQ) ${ }^{16}$ and LCADL scale ${ }^{17}$ were applied. In the third assessment, simulation of ADLs set in an appropriate laboratory was performed. All scales and questionnaires were applied by the same examiner in an interview in a quiet environment to minimize possible bias.

\section{MMRC Dyspnea Scale}

The MMRC scale consists of 5 items; the patient chooses the one that best represents his or her perception of dyspnea in ADLs. It was validated ${ }^{8}$ for the Brazilian population. ${ }^{14}$ The modified scale has the same interpretation, but score ranges from 0 to 4 , with higher values indicating greater limitation by dyspnea in ADL performance.

\section{SGRQ}

The SGRQ was proposed and validated for patients with chronic respiratory diseases ${ }^{18}$ and translated and validated for the Brazilian population. ${ }^{19}$ The questionnaire approaches aspects related to 3 areas: symptoms, which relate to discomfort caused by respiratory symptoms; activity, which relates to changes in physical activity; and impact, which assesses the overall impact on ADLs and patient wellness. Each domain has a maximum possible score, with points added for each response and referred to as a percentage of this maximum. Values above $10 \%$ reflect a quality of life changed in that domain. In addition to the score of each domain, a total score is obtained, and a higher score is related to poorer quality of life. ${ }^{18,19}$

\section{LCADL Scale}

The LCADL scale was proposed and validated for patients with $\mathrm{COPD}^{9}$ and was translated and validated for the Portuguese population. ${ }^{17}$ It consists of 4 domains: selfcare, domestic, physical, and leisure. The LCADL scale can assess the degree of dyspnea in ADLs because it is composed of 15 quantitative questions encompassing ADLs such as putting on a shirt, putting on shoes, making the bed, and drying after showering. Subjects indicate a score of $0-5$, with the largest value representative of maximum inability to perform ADLs. Together, these scores account for a total of 75 points. A higher total score indicates greater limitation in performing ADLs due to dyspnea. ${ }^{9}$ One can also examine the scale as a percentage of the total score (LCADL\%); for this, the percentage score for each area is calculated in relation to the maximum score allowed, that is, if the patient scores zero (cannot perform this activity because I have never needed to or it is irrelevant) for any item, it will be disregarded in the calculation of LCADL\%. Thus, a new maximum value is obtained, subtracting 5 points for each item disregarded.

\section{6-min Walk Distance}

The 6-min walk test was performed according to the standards of the American Thoracic Society. ${ }^{15}$ Two tests were performed with an interval of $30 \mathrm{~min}$. The greatest distance walked was considered for statistical analysis. The percent of predicted, described by Iwama et al, ${ }^{20}$ was determined after testing.

\section{ADL Assessment}

Simulation of ADLs was carried out in an adapted laboratory within the School Health Unit belonging to the university. These included getting out of bed, putting on shoes, making the bed, showering, lifting and lowering containers on a shelf above the shoulder girdle, and raising and lowering pots on a shelf below the pelvic girdle (Fig. 1). The activities were carried out in the aforementioned order, as a circuit, with no breaks between activities, and the subjects were instructed to perform the activities as they do at home, with free time to their execution. The runtime was recorded to compare the total time to complete the circuit.

$\mathrm{S}_{\mathrm{pO}_{2}}$ (model 2500, Nonin, Plymouth, Minnesota) and dyspnea (Borg category ratio 10 ) were monitored during rest and immediately after the execution of each of the ADLs. Breathing frequency and blood pressure were measured at rest and at the end of the ADL circuit, and heart rate was monitored during the execution of all ADLs.

\section{Statistical Analysis}

The statistical program SPSS 17.0.0 (SPSS, Chicago, Illinois) was used for statistical analysis. The ShapiroWilk test was used to assess the normality of the data. The variables that had a normal distribution were described as 


\section{Limitation of Activities of DaILy Living AND COPD}
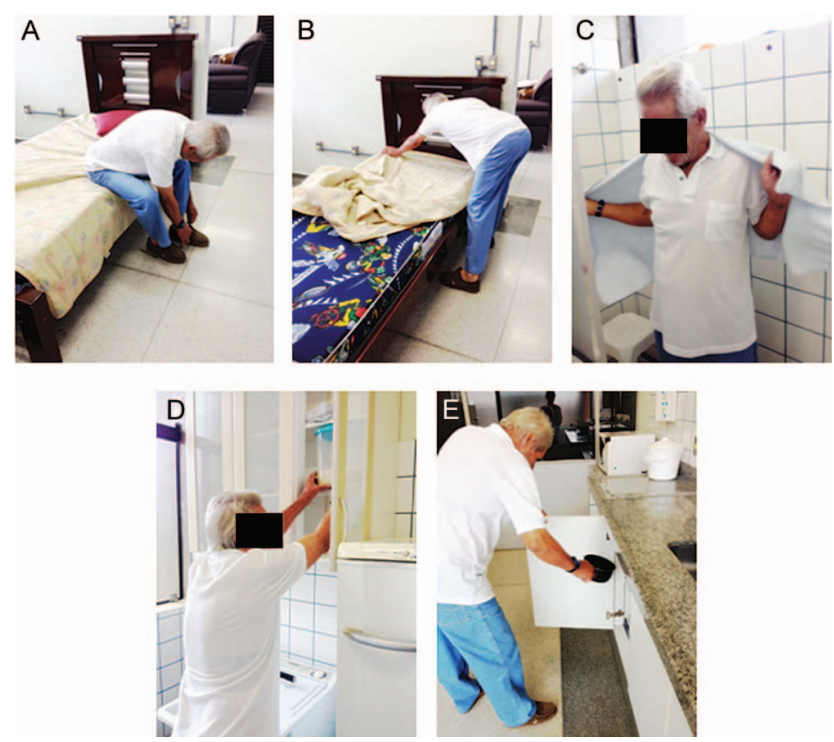

Fig. 1. Subject with COPD performing activities of daily living. A: Getting out of bed and putting on shoes. B: Making the bed. C: Taking a shower. D: Raising and lowering containers on a shelf above the scapular girdle. E: Raising and lowering items on a shelf below the pelvic girdle.

mean $\pm \mathrm{SD}$, whereas the variables without normal distribution were described as median (interquartile range). Analysis of variance with the Tukey post hoc test and its nonparametric equivalent, the Kruskall-Wallis test with the Mann-Whitney post hoc test with Bonferroni correction, were used to compare variables between the 4 GOLD groups.

To verify the degree of association between oxygen desaturation and dyspnea while performing ADLs in GOLD groups A-D, cutoff points were determined for these variables for further analysis and application of the chi-square test. For dyspnea, a 1-point increase on the Borg scale was considered as indicative of the presence of dyspnea in ADL performance according to Ries. ${ }^{21}$ Oxygen desaturation was taken as values below $88 \%$, according to Andrianopoulos et $\mathrm{al},{ }^{22}$ and $4 \%$ decrease in $\mathrm{S}_{\mathrm{pO}_{2}}$, according to Dal Corso et al. ${ }^{23}$

Furthermore, changes in $\mathrm{S}_{\mathrm{pO}_{2}}$ and dyspnea before and after the end of each ADL were determined. The correlation between these variables was determined using the Spearman correlation coefficient, as these variables had abnormal distributions, and was subsequently plotted in a scatter plot.

A significance level of $P \leq .05$ was adopted. To detect the power of the test, G*Power 3.1.3 (Universität Düsseldorf, Düsseldorf, Germany) was used. We used LCADL\%, total SGRQ score, and $\mathrm{S}_{\mathrm{pO}_{2}}$ ADLs to determine a power of $>95 \%$ for these variables. For dyspnea in ADL performance, we determined a power of $<80 \%$.

\section{Results}

Of 50 subjects who fulfilled the inclusion criteria, 6 were excluded, so 44 subjects completed all assessments (Fig. 2). The subjects' mean age was $69 \pm 8.8 \mathrm{y}$, with a mean $\mathrm{FEV}_{1} / \mathrm{FVC}$ of $0.51 \pm 0.12$ and a mean $\mathrm{FEV}_{1}$ of $1.3 \pm 0.51 \mathrm{~L}(49 \pm 15.7 \%$ of predicted $)$. Of the 44 subjects who completed the study, 26 (59\%) had exacerbations during the year preceding the study.

\section{Clinical Characteristics of Subjects Grouped According to COPD Combined Evaluation}

Table 1 shows the demographic and clinical characteristics of subjects classified by GOLD 2011. There was no statistical difference in age, presence of comorbidities, smoking history, or body mass index between groups.

In addition, Table 1 shows that subjects in groups $\mathrm{C}$ and D had statistically lower $\mathrm{FEV}_{1}$ and shorter 6-min walk distances. As expected, the MMRC scores were statistically higher in subjects in groups B and D. Subjects in groups $\mathrm{B}-\mathrm{D}$ were found to have higher BODE indexes compared with subjects in group A.

There was no statistical difference between groups with regard to use of home oxygen therapy. Subjects in group $\mathrm{D}$ had a higher number of exacerbations compared with subjects in groups A and B.

\section{ADL Limitations and COPD Combined Assessment}

There was no significant difference between groups when measuring the runtime of ADLs. We verified that there was no significant difference between groups with regard to the presence of oxygen desaturation during ADLs performed on the circuit (Table 2) and no association between the risk groups and the presence of oxygen desaturation (Table 3). Although all subjects had an $\mathrm{S}_{\mathrm{pO}_{2}}$ of $>90 \%$ at rest, there were subjects in all 4 groups who had a decrease in $\mathrm{S}_{\mathrm{pO}_{2}}$ of $>4 \%$ or an $\mathrm{S}_{\mathrm{pO}_{2}}$ of $<88 \%$. As expected, the largest percentage of low $\mathrm{S}_{\mathrm{pO}_{2}}$ was found in group D, with $53 \%$ of subjects showing an $\mathrm{S}_{\mathrm{pO}_{2}}$ of $<88 \%$ in ADLs, such as showering and lowering pots below the pelvic girdle. On the other hand, $\sim 41 \%$ of subjects in this group demonstrated a decrease in $\mathrm{S}_{\mathrm{pO}_{2}}$ of $\geq 4 \%$ during showering.

There were no significant associations or differences in dyspnea in the 4 groups (see Table 2); however, in all groups, there were subjects who experienced dyspnea while performing ADLs (see Table 3), with this being more evident in subjects in group D. Furthermore, there was no correlation between the change in dyspnea and $\mathrm{S}_{\mathrm{pO}_{2}}$ during the performance of ADLs, as shown in Figure 3.

On the LCADL scale (see Table 2), group D subjects presented higher values than group A subjects in the self- 


\section{Limitation of Activities of Daily Living AND COPD}

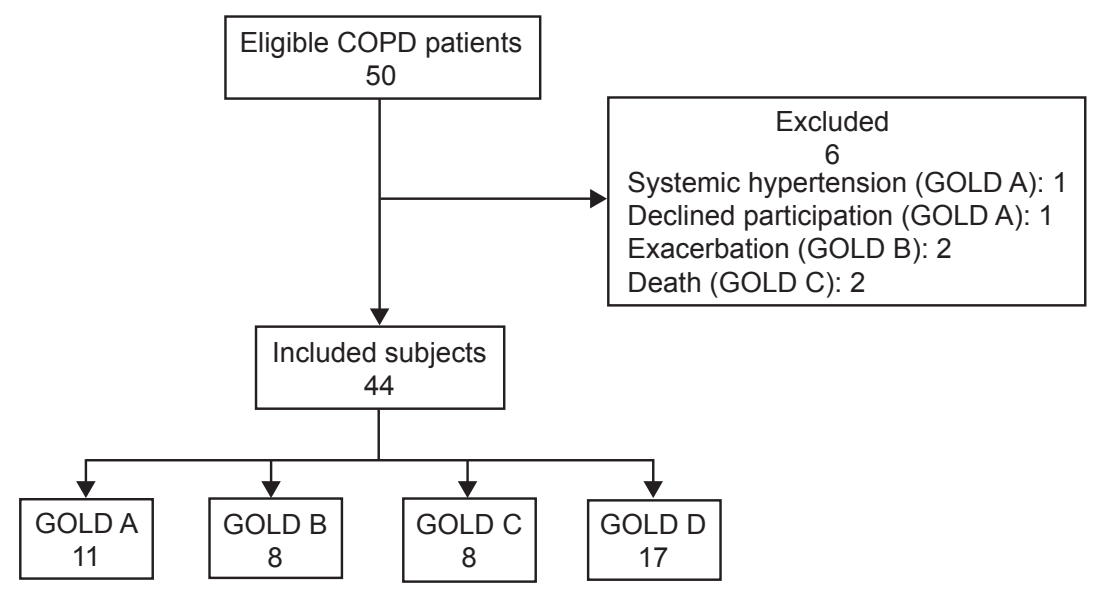

Fig. 2. Flow chart of inclusion and exclusion of subjects in the study and the COPD combined classification with association between symptoms, spirometric classification, and future risk of exacerbation. Global Initiative for Chronic Obstructive Lung Disease (GOLD) $A=$ low risk, fewer symptoms; GOLD 1 or 2; $\leq 1$ exacerbation/y; Modified Medical Research Council (MMRC) 0-1. GOLD B = low risk, more symptoms; GOLD 1 or $2 ; \leq 1$ exacerbation/y; MMRC $\geq 2$. GOLD C = high risk, fewer symptoms; GOLD 3 or 4 ; $\geq 2$ exacerbations/y; MMRC $0-1$. GOLD D $=$ high risk, more symptoms; GOLD 3 or $4 ; \geq 2$ exacerbations/y; MMRC $\geq 2$.

Table 1. Anthropometric and Clinical Data of the Sample, Classification of Dyspnea, and 6MWD

\begin{tabular}{|c|c|c|c|c|c|}
\hline & \multicolumn{4}{|c|}{ GOLD Group } & \multirow[b]{2}{*}{$P$} \\
\hline & $\mathrm{A}(n=11)$ & $\mathrm{B}(n=8)$ & $\mathrm{C}(n=8)$ & $\mathrm{D}(n=17)$ & \\
\hline Males, $n$ & 11 & 7 & 6 & 13 & \\
\hline Age $($ mean $\pm S D), y$ & $66 \pm 10.5$ & $72.2 \pm 10.1$ & $67 \pm 4.6$ & $71.5 \pm 8.3$ & .34 \\
\hline Smoking history (mean $\pm \mathrm{SD}$ ), pack-years & $101 \pm 70$ & $60.6 \pm 24.9$ & $58.9 \pm 42.7$ & $60.7 \pm 42.8$ & .15 \\
\hline Charlson comorbidity index, median (interquartile range) & $1(1-2)$ & $1(1-2.5)$ & $1(2.2-4.7)$ & $1(1-1)$ & .46 \\
\hline $\mathrm{S}_{\mathrm{pO}_{2}}$ at rest (mean $\left.\pm \mathrm{SD}\right), \%$ & $93 \pm 2$ & $93 \pm 2$ & $93 \pm 2$ & $93 \pm 2$ & .83 \\
\hline $\mathrm{BMI}($ mean $\pm \mathrm{SD}), \mathrm{kg} / \mathrm{m}^{2}$ & $25.7 \pm 4.5$ & $24.3 \pm 4.5$ & $24.7 \pm 5.4$ & $23.0 \pm 4.6$ & .53 \\
\hline $\mathrm{FEV}_{1}($ mean $\pm \mathrm{SD}), \mathrm{L}$ & $1.72 \pm 0.2$ & $1.8 \pm 0.3$ & $1.0 \pm 0.3 \neq \S$ & $0.9 \pm 0.4 \ddagger \S$ & $<.001^{*}$ \\
\hline $\mathrm{FEV}_{1}($ mean $\pm \mathrm{SD}), \%$ predicted & $62 \pm 9.2$ & $62.9 \pm 10.1$ & $40.6 \pm 6+\S$ & $39.5 \pm 14.2 \ddagger \S$ & $<.001 *$ \\
\hline MMRC, median (interquartile range) & $1(1-1)$ & $2(2-2.75) \ddagger$ & $1(0-1) \S$ & $2(2-3.5) \neq \|$ & $<.001 \dagger$ \\
\hline $6 \mathrm{MWD}($ mean $\pm \mathrm{SD}), \mathrm{m}$ & $487 \pm 50.7$ & $371.6 \pm 140.1) \neq$ & $354.7 \pm 53.8 \ddagger$ & $352.7 \pm 84.2 \ddagger$ & $.001 *$ \\
\hline $6 \mathrm{MWD}($ mean $\pm \mathrm{SD}), \%$ predicted & $86.8 \pm 8.1$ & $67.1 \pm 24.4) \neq$ & $65 \pm 8.8 \ddagger$ & $65.5 \pm 14.8 \ddagger$ & $.003^{*}$ \\
\hline BODE index, median (interquartile range) & $0.5(0-1)$ & $3(1.2-3) \ddagger$ & $3(2.2-4.7) \ddagger$ & $5(2-3) \ddagger \S$ & $<.001 \dagger$ \\
\hline BODE quartile, median (interquartile range) & $1(1-1)$ & $2(1-3)$ & $2(1.2-1) \ddagger$ & $3(2-3) \neq$ & $<.001 \dagger$ \\
\hline Exacerbation history, $n(\%)$ & $4(36)$ & $2(25)$ & $5(62.5)$ & $15(88.2) \ddagger \S$ & $.002 \dagger$ \\
\hline Oxygen use, $n(\%)$ & 0 & $1(12.5)$ & $1(12.5)$ & $2(11.8)$ & \\
\hline \multicolumn{6}{|l|}{ Drugs, $n(\%)$} \\
\hline Bronchodilator & $5(45.5)$ & $1(12.5)$ & 0 & $3(17.6)$ & \\
\hline Bronchodilator + inhaled corticosteroids & $6(54.5)$ & $7(87.5)$ & $8(100)$ & $13(76.5)$ & \\
\hline Systemic corticosteroids & 0 & 0 & 0 & $1(5.9)$ & \\
\hline $\begin{array}{l}* P \leq .05 \text { (one-way analysis of variance with Tukey post hoc) } \\
\dagger P \leq .05 \text { (Kruskal-Wallis test with Mann-Whitney post hoc and Bonferroni } \\
¥ \text { Significant differences between groups A vs B, C, and D } \\
\S \text { Significant differences between groups B vs C and D } \\
\| \text { Significant differences between groups C vs D } \\
\text { GOLD = Global Initiative for Chronic Obstructive Lung Disease } \\
\text { BMI = body mass index } \\
\text { MMRC = Modified Medical Research Council } \\
\text { 6MWD = 6-min walk distance }\end{array}$ & ection) & & & & \\
\hline
\end{tabular}

care domain. In the domestic domain, group C subjects had statistically lower values than group A subjects, and in the leisure domain, group D subjects had notably higher values compared with group C subjects. Finally, subjects in groups B and D had statistically higher overall percentage scores compared with subjects in group A. 


\section{Limitation of Activities of Daily Living ANd COPD}

Table 2. Comparison Between Groups With Regard to Quality of Life, Dyspnea in Daily Living, and Change in Oxygen Saturation and Dyspnea in the ADL Simulation

\begin{tabular}{|c|c|c|c|c|c|}
\hline & \multicolumn{4}{|c|}{ GOLD Group } & \multirow[b]{2}{*}{$P$} \\
\hline & $\mathrm{A}(n=11)$ & $\mathrm{B}(n=8)$ & $\mathrm{C}(n=8)$ & $\mathrm{D}(n=17)$ & \\
\hline \multicolumn{6}{|l|}{ SGRQ, \% } \\
\hline Symptoms & $29.6 \pm 12$ & $28.2 \pm 22.7$ & $26.6 \pm 17$ & $47.7 \pm 21.1 \|$ & $.02 *$ \\
\hline Activities & $37 \pm 16.1$ & $59.8 \pm 12.8+$ & $36.9 \pm 22.5$ & $69.9 \pm 12.3 \|$ & $<.001^{*}$ \\
\hline Impact & $18.3 \pm 14.1$ & $33.2 \pm 10.6$ & $20.2 \pm 19.1$ & $38 \pm 15.5 \|$ & $.005^{*}$ \\
\hline Total & $25.8 \pm 12.4$ & $41.8 \pm 9.4$ & $26.9 \pm 18$ & $49.3 \pm 12.5 \|$ & $<.001^{*}$ \\
\hline \multicolumn{6}{|l|}{ LCADL scale } \\
\hline Self-care & $4(4-5)$ & $5(5-5)$ & $5(4.2-6.7)$ & $6(4.5-8) \ddagger$ & $.02 \dagger$ \\
\hline Domestic & $5(4-6)$ & $3(0-4.7)$ & $2(0-2.7) \ddagger$ & $5(0-8.5)$ & $.05 \dagger$ \\
\hline Physical & $3(3-4)$ & $4(4-5)$ & $3(2-5)$ & $4(3-5.5)$ & .051 \\
\hline Leisure & $3(3-4)$ & $4(3-4)$ & $3(3-3) \S$ & $4(2-5) \|$ & $.005 \dagger$ \\
\hline Total & $16(14-18)$ & $15(14-18.2)$ & $13(9.7-17)$ & $20(13-22) \|$ & .02 \\
\hline Total \% & $23(21-25)$ & $28(25-31) \ddagger$ & $24(21-30)$ & $30(26-42) \neq$ & $.004 \dagger$ \\
\hline \multicolumn{6}{|l|}{ ADL simulation } \\
\hline Total time, $\min$ & $13.6 \pm 1.8$ & $15.2 \pm 4.5$ & $13.2 \pm 2.2$ & $14.9 \pm 2.3$ & .32 \\
\hline \multicolumn{6}{|l|}{$\Delta \mathrm{S}_{\mathrm{pO}_{2}}$} \\
\hline Making the bed & $-1(-3$ to 0$)$ & $-1(-2.7$ to -1$)$ & $-0.5(-2-0)$ & $-3(-4.5$ to 0$)$ & .70 \\
\hline Showering & $-1(-2$ to 0$)$ & $-1.5(-2.7$ to -1$)$ & $-2.5(-4.5$ to 1.2$)$ & $-3(-5$ to -1.5$)$ & .61 \\
\hline Lifting containers above the scapular girdle & $-1(-3$ to 0$)$ & $-2(-5$ to 0.2$)$ & $-1.5(-13$ to -0.2$)$ & $-3(-4$ to -0.5$)$ & .37 \\
\hline Lowering pots below the pelvic girdle & $0(-1$ to 1$)$ & $-1(-4$ to 0$)$ & $-0.5(-13$ to 0$)$ & $-1(-6.5$ to 0$)$ & .56 \\
\hline \multicolumn{6}{|l|}{$\Delta$ Dyspnea } \\
\hline Making the bed & $0(0-1)$ & $0.5(0-1)$ & $0(0-0.5)$ & $0.5(0-1.5)$ & .48 \\
\hline Showering & $0.5(-0.5-1)$ & $1(1-2)$ & $1(0.25-1.75)$ & $1(0-2.5)$ & .06 \\
\hline Lifting containers above the scapular girdle & $0.5(0-2)$ & $1(0-2.75)$ & $1(0.25-1.75)$ & $1(0.25-2.75)$ & .49 \\
\hline Lowering pots below the pelvic girdle & $1(-0.5-1.5)$ & $1(0-3.75)$ & $1(0.25-1)$ & $1(0-2.75)$ & .07 \\
\hline $\begin{array}{l}\text { Values are expressed as mean } \pm \text { SD or median (interquartile rang } \\
* P \leq .05 \text { (one-way analysis of variance with Tukey post hoc) } \\
\dagger P \leq .05 \text { (Kruskal-Wallis test with Mann-Whitney post hoc and } \\
¥ \text { Significant differences between groups A vs B, C, and D } \\
\text { \& Significant differences between groups B vs C and D } \\
\| \text { Significant differences between groups C vs D } \\
\text { ADL = activity of daily living } \\
\text { GOLD = Global Initiative for Chronic Obstructive Lung Disease } \\
\text { SGRQ = St George Respiratory Questionnaire } \\
\text { LCADL = London Chest Activity of Daily Living } \\
\Delta=\text { value in activities - basal value. }\end{array}$ & ferroni correction) & & & & \\
\hline
\end{tabular}

\section{Quality of Life and COPD Combined Assessment}

The quality of life assessment comparison between groups (see Table 2) performed using the SGRQ revealed a significant difference in the activity domain among the groups except between groups A and C. As for the symptom domain, group D had higher values compared with group C.

When comparing the impact domain and the total score, group D subjects had statistically higher scores than group $\mathrm{A}$ and $\mathrm{C}$ subjects. In relation to the total score, the average score in less symptomatic groups (A and $\mathrm{C}$ ) was 2 times lower than that in the more symptomatic groups (B and $\mathrm{D})$.

\section{Discussion}

We showed that there was no association between groups when using the COPD combined assessment regarding the presence of oxygen desaturation and dyspnea in the execution of ADLs. However, we found that, in all groups proposed by GOLD 2011, there were subjects who demonstrated oxygen desaturation during ADLs, with the greatest percentage in group D. The main unsupported activities included flexion of the trunk and lifting of arms. All groups had subjects who reported dyspnea during ADL simulation. Group D subjects had greater ADL dyspnea as assessed by the LCADL scale. Compared with less symptomatic subjects, group D subjects had a poorer quality of life as assessed by the SGRQ. 
Table 3. Number of Subjects With a Decrease in $\mathrm{S}_{\mathrm{pO}_{2}}$ of $\geq 4 \%, \mathrm{~S}_{\mathrm{pO}_{2}}$ of $<88 \%$, and Difference From Rest to Exercise of $\geq 1$ Point on the Borg Dyspnea Scale in ADL Simulation

\begin{tabular}{|c|c|c|c|c|c|}
\hline & \multicolumn{4}{|c|}{ GOLD Group } & \multirow{2}{*}{$P^{*}$} \\
\hline & $\mathrm{A}(n=11)$ & $\mathrm{B}(n=8)$ & $\mathrm{C}(n=8)$ & $\mathrm{D}(n=17)$ & \\
\hline \multicolumn{6}{|l|}{$\Delta \mathrm{S}_{\mathrm{pO}_{2}} \geq 4 \%, n(\%)$} \\
\hline Making the bed & $1(9.1)$ & $1(12.5)$ & $2(25)$ & $8(47.1)$ & .11 \\
\hline Showering & $1(9.1)$ & $2(25)$ & $2(25)$ & $7(41.2)$ & .32 \\
\hline Lifting containers above the scapular girdle & $2(18.2)$ & $3(37.5)$ & $4(50)$ & $8(47.1)$ & .41 \\
\hline Lowering pots below the pelvic girdle & $1(9.1)$ & $3(37.5)$ & $4(50)$ & $5(29.4)$ & .26 \\
\hline \multicolumn{6}{|l|}{$\mathrm{S}_{\mathrm{pO}_{2}}<88 \%, n(\%)$} \\
\hline Making the bed & $1(9.1)$ & $1(12.5)$ & $1(12.5)$ & $5(29.4)$ & .49 \\
\hline Showering & $2(18.2)$ & $3(37.5)$ & $4(50)$ & $9(52.9)$ & .30 \\
\hline Lifting containers above the scapular girdle & $1(9.1)$ & $3(37.5)$ & $3(37.5)$ & $7(41.2)$ & .32 \\
\hline Lowering pots below the pelvic girdle & $1(9.1)$ & $1(12.5)$ & $3(37.5)$ & $6(53.3)$ & .29 \\
\hline \multicolumn{6}{|l|}{$\Delta$ Dyspnea $>1$ point on the BORG scale, $n(\%)$} \\
\hline Making the bed & $3(27.3)$ & $4(50)$ & $1(12.5)$ & $8(47.1)$ & .28 \\
\hline Showering & $4(36.4)$ & $4(50)$ & $6(75)$ & $9(52.9)$ & .43 \\
\hline Lifting containers above the scapular girdle & $5(45.5)$ & $5(62.5)$ & $6(75)$ & $11(64.7)$ & .60 \\
\hline Lowering pots below the pelvic girdle & $6(54.5)$ & $5(62.5)$ & $6(75)$ & $10(58.8)$ & .83 \\
\hline $\begin{array}{l}\text { * Chi-square test } \\
\text { ADL = activity of daily living } \\
\text { GOLD = Global Initiative for Chronic Obstructive Lung Disease }\end{array}$ & & & & & \\
\hline
\end{tabular}

In addition, we also noticed that subjects with COPD developed a transient decrease in $\mathrm{S}_{\mathrm{pO}_{2}}$ and dyspnea during ADLs, especially while performing activities such as walking, showering, and eating. ${ }^{24} \mathrm{~A}$ decrease in $\mathrm{S}_{\mathrm{pO}_{2}}$ and dyspnea could also accelerate the progress of the disease. Therefore, despite the fact that there are aspects yet to be confirmed, we suggest that there could be a relationship between the GOLD groups and oxygen desaturation and dyspnea.

Nevertheless, the largest percentage of subjects demonstrating oxygen desaturation belonged to group D. In this case, however, the desaturation, which was characterized by $\Delta \mathrm{S}_{\mathrm{pO}_{2}}$ of $>4 \%$, occurred mainly during activities such as making the bed (47.1\%) and lifting containers above the girdle $(47.1 \%)$. This was also true regarding the presence of an $\mathrm{S}_{\mathrm{pO}_{2}}$ of $<88 \%$. In the other groups, there were also subjects who demonstrated oxygen desaturation, which makes it possible to infer that subjects with COPD can experience ADL limitation regardless of the risk group in which they are classified. In other words, it is necessary to be aware of this limitation in spite of the classification made by the COPD combined assessment. Although the COPD combined assessment was created in an attempt to minimize problems in a simplified classification of these patients, it may not have been the best option to identify patients presenting with oxygen desaturation because the factors involved in this mechanism are not encompassed in the assessment.

A recent study 22 demonstrated that non-hypoxic subjects, who have an $\mathrm{FEV}_{1}$ of $<45 \%$ of predicted, generally have an $\mathrm{S}_{\mathrm{pO}_{2}}$ of $\leq 88 \%$ during walking activities, confirming the findings of our study showing that the highest prevalence of subjects with an $\mathrm{S}_{\mathrm{pO}_{2}}$ of $<88 \%$ were in groups $\mathrm{C}$ and $\mathrm{D}$, who also had an $\mathrm{FEV}_{1}$ of $<50 \%$ of predicted. Oxygen desaturation was present in these subjects due to an imbalance between oxygen supply and demand during the exercise, what could be attributed to respiratory, hemodynamic, and peripheral muscle disorders or a combination of these. ${ }^{25}$

It is important to note that the selected activities for ADL simulation included a great range of upper limb motions with different degrees of chest muscle involvement to assess not only one isolated ADL but most of the subjects' home activities. Considering this, free time to run the ADLs was determined in the assessments to simulate exactly how the subject would do it at home, and this was similar between groups, with means of 13 min for group A, 15 min for groups B and D, and 13 min for group C, with no statistically significant difference.

Elevating pots with different weights is a very dynamic activity, involving broad movements, especially the shoulders, besides maintenance of the upper limbs without support. This type of activity leads to increased minute ventilation by $60-70 \%$ of maximum voluntary ventilation, with a consequent drop in metabolic and ventilatory reserves associated with a decrease in $\mathrm{S}_{\mathrm{pO}_{2}}$ and subsequent hypoxemia, ${ }^{26}$ which could explain the findings of this study. In contrast, when considering activities involving trunk flexion, such as making the bed and putting on shoes, 

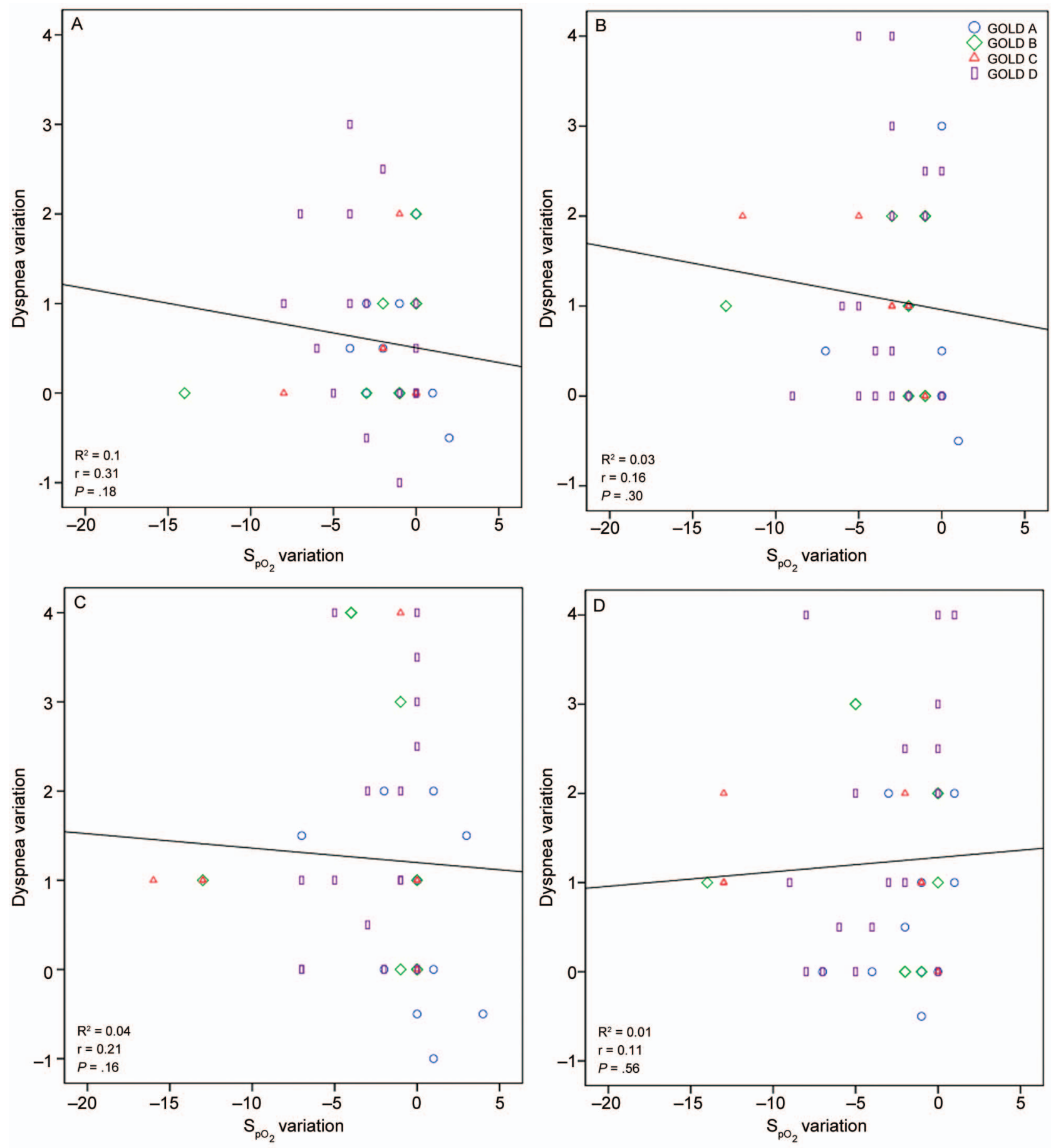

Fig. 3. Scatter plots of the variation of dyspnea and peripheral $\mathrm{S}_{\mathrm{pO}_{2}}$ in activities of daily living according to Global Initiative for Chronic Obstructive Lung Disease (GOLD) group. A: Getting up, putting on shoes, and making the bed. B: Taking a shower. C: Raising and lowering items below the pelvic girdle; D: Raising and lowering items above the scapular girdle.

subjects had a rapid, shallow, and irregular breathing pattern, ${ }^{27}$ which can explain the presence of oxygen desaturation while performing the activities.

In this study, we found that in all 4 GOLD groups, there were subjects who reported dyspnea in ADL performance, which was assessed by the Borg scale. Impairment of rib cage mechanics and gas exchange inefficiency were prominent in subjects with COPD and contributed to an increase in respiratory effort, which occurred with the onset of dyspnea. ${ }^{28}$ 


\section{Limitation of Activities of Daily Living ANd COPD}

When assessed by the Borg scale, dyspnea not only involves the perception of breathlessness but also welfare, discomfort, and difficulty in ADL performance, ${ }^{26}$ this being one of the most important factors in limiting ADL execution in patients with COPD. ${ }^{29-31}$ Thus, it becomes important to focus on subjects with fewer symptoms because despite not reporting dyspnea when the ADL rating scales are applied, they do report dyspnea when simulating ADLs, with limitation in performing ordinary activities.

Reported dyspnea assessed by the MMRC scale is widely used to measure breathlessness in patients, as it is an easy, quick, and simple tool. ${ }^{8}$ In the 2011 update, GOLD proposed that this tool should be used to provide a complete evaluation of patients as long as it considers not only the air-flow limitation but also the symptoms and future risk of exacerbations. ${ }^{3}$

As a consequence, when assessed by the MMRC scale, subjects who presented with fewer symptoms (groups A and C) showed representative values of dyspnea while performing ADLs, and in these groups, the median for the MMRC scale was 1, which indicated the presence of dyspnea when the subject walked fast or climbed up a slope. While lifting containers above the shoulder girdle, $45 \%$ of group A subjects and $75 \%$ of group C subjects had a variation of $>1$ point on the Borg scale. Considering this, it was possible to conclude that dyspnea reported by the MMRC scale does not exactly reflect the dyspnea reported while performing ADLs. This can be explained by the fact that the small number of ADLs that compose this scale ${ }^{32}$ do not reflect all ADLs performed on the circuit proposed by this study, and probably not the ones performed in a subject's home.

In the study by Vaes et al, ${ }^{32}$ oxygen consumption and dyspnea were evaluated while subjects performed ADLs. The subjects were stratified by sex, GOLD stage, MMRC score, and BODE index. The authors concluded that subjects classified as GOLD stage IV with an MMRC score of 5 and a score $\geq 6$ in the BODE index have higher oxygen consumption and a greater perception of dyspnea while performing ADLs. They also found that subjects classified as GOLD stage II have a greater perception of dyspnea compared with healthy subjects. In that case, the subjects used a higher proportion of their peak aerobic and ventilatory capacity in contrast to the findings of our study, in which we found no association between subject stratification by the COPD combined classification and the presence of dyspnea during ADL performance. Nevertheless, it was verified that subjects belonging to the less symptomatic group also reported dyspnea while performing some ADLs. Because dyspnea is the trigger point for the beginning of the sedentary-dyspnea cycle, ${ }^{7}$ evaluation of this symptom in limiting ADLs is important, and as is inclusion of subjects in pulmonary rehabilitation programs to delay progression of this cycle. Oxygen desaturation not linearly attached to dyspnea is important to consider and emphasizes the need to assess dyspnea even in patients without oxygen desaturation.

Another important finding was the lack of correlation between dyspnea and oxygen desaturation during ADL performance, which could be a consequence of independent and unrelated behaviors. For instance, desaturation could occur because of an imbalance between the oxygen available and the amount demanded while exercising. This could be attributed not only to respiratory disorders, but also to hemodynamic and peripheral muscle disorders or a combination of all. ${ }^{24}$

The magnitude of dyspnea could depend on a diverse range of mechanisms, such as an increase in ventilatory needs due to physiological alterations of dead space, pulmonary overinflation, hypoxemia, hypercapnia, early lactic acidosis or peripheral and respiratory muscle weakness. It could also be associated with physical deconditioning or systemic and airway inflammation. ${ }^{33,34}$

Coupled with the Borg and MMRC scales, the LCADL scale is widely used for a more specific evaluation of ADL dyspnea sensation. In this study, we found that subjects in groups B and D had higher percentages for the total LCADL score, averaging $28 \%$ and $30 \%$, respectively, compared with group A (23\%). Confirming the findings of this study, the EDIP-EPOC I and II studies ${ }^{35}$ showed that subjects with severe or very severe COPD had higher scores for each of the 15 ADLs described for LCADL scale compared with those with moderate COPD, thus showing that the severity of the disease has a major impact on all functional aspects of a patient's life. ${ }^{11}$

Studies show that patients with an $\mathrm{FEV}_{1}$ of $<50 \%$ of predicted have a decreased quality of life; this value is a critical factor for quality of life and an indicator of general health. ${ }^{11,36,37}$ In addition, Hsu et al ${ }^{38}$ demonstrated that the MMRC scale is able to detect early deterioration in quality of life, which could explain our study results showing that group B and D subjects had higher scores on the MMRC scale but a poorer quality of life, with means of $41.8 \%$ and $49.3 \%$, respectively, in the SGRQ. This also shows a possible relationship between the score on the MMRC scale and quality of life.

The results of this study may have been limited by the small number of subjects, particularly in groups B and C, which may have contributed to the lack of association between the groups proposed by the COPD combined assessment and oxygen desaturation and dyspnea while performing ADLs.

\section{Conclusions}

The assessment of ADL limitations was based not only on the combined evaluation of COPD but also on the simulation of ADLs. This is because those subjects clas- 


\section{Limitation of Activities of Daily Living AND COPD}

sified as mildly symptomatic may have had dyspnea and oxygen desaturation while performing ADLs. When it is not possible to simulate ADLs, it is necessary to apply more specific scales (such as LCADL) for evaluation of dyspnea in ADL performance. These additions would allow profiles to be made of those patients who have greater ADL limitations.

Based on the results of this study, in which we used the COPD combined assessment to support our findings, it was not possible to determine those subjects who had oxygen desaturation and dyspnea while performing ADLs. Therefore, further studies are needed to strengthen our findings. In contrast, the subjects in the more symptomatic group, who had the highest risk of exacerbation, presented the poorest quality of life and the highest intensity of dyspnea during ADL performance as assessed by the LCADL scale.

\section{REFERENCES}

1. Vestbo J, Hurd SS, Agustí AG, Jones PW, Vogelmeier C, Anzueto A, et al. Global strategy for the diagnosis, management, and prevention of chronic obstructive pulmonary disease: GOLD executive summary. Am J Respir Crit Care Med 2013;187(4):347-365.

2. Agustí A, Calverley PM, Celli B, Coxson HO, Edwards LD, Lomas DA, et al. Characterisation of COPD heterogeneity in the ECLIPSE cohort. Respir Res 2010;11:122.

3. Global Initiative for Chronic Obstructive Lung Disease (GOLD). Global strategy for the diagnosis, management, and prevention of COPD. Updated 2014. http://www.goldcopd.org. Accessed October 16, 2014.

4. Nici L, Donner C, Wouters E, Zuwallack R, Ambrosino N, Bourbeau $\mathrm{J}$, et al. American Thoracic Society/European Respiratory Society statement on pulmonary rehabilitation. Am J Respir Crit Care Med 2006;173(12):1390-1413.

5. Skumlien S, Hagelund T, Bjørtuft O, Ryg MS. A field test of functional status as performance of activities of daily living in COPD patients. Respir Med 2006;100(2):316-323.

6. Cutaia M, Brehm R, Cohen M. The relationship of the BODE index to oxygen saturation during daily activities in patients with chronic obstructive pulmonary disease. Lung 2011;189(4):269-277.

7. Polkey MI, Moxham J. Attacking the disease spiral in chronic obstructive pulmonary disease. Clin Med 2006;6(2):190-196.

8. Bestall JC, Paul EA, Garrod R, Garnham R, Jones PW, Wedzicha JA. Usefulness of the Medical Research Council (MRC) dyspnoea scale as a measure of disability in patients with chronic obstructive pulmonary disease. Thorax 1999;54(7):581-586.

9. Garrod R, Bestall JC, Paul EA, Wedzicha JA, Jones PW. Development and validation of a standardized measure of activity of daily living in patients with severe COPD: the London Chest Activity of Daily Living scale (LCADL). Respir Med 2000;94(6):589-596.

10. Kinsman RA, Yaroush RA, Fernandez E, Dirks JF, Schocket M, Fukuhara J. Symptoms and experiences in chronic bronchitis and emphysema. Chest 1983;83(5):755-761.

11. Hajiro T, Nishimura K, Tsukino M, Ikeda A, Oga T, Izumi T. A comparison of the level of dyspnea vs disease severity in indicating the health-related quality of life of patients with COPD. Chest 1999; 116(6):1632-1637.

12. Reardon JZ, Lareau SC, ZuWallack R. Functional status and quality of life in chronic obstructive pulmonary disease. Am J Med 2006; 119(10 Suppl 1):32-37.
13. Marchiori RC, Susin CF, Dal Lago L, Felice CD, Brandão da Silva D, Severo MD. Diagnosis and treatment of COPD exacerbated in emergency. Revista da AMRIGS 2010;54(2):214-223.

14. Kovelis D, Segretti NO, Probst VS, Lareau SC, Brunetto AF, Pitta F. Validation of the Modified Pulmonary Functional Status and Dyspnea Questionnaire and the Medical Research Council scale for use in Brazilian patients with chronic obstructive pulmonary disease. J Bras Pneumol 2008;34(12):1008-1018.

15. ATS Committee on Proficiency Standards for Clinical Pulmonary Function Laboratories. ATS statement: guidelines for the six-minute walk test. Am J Respir Crit Care Med 2002;166(1):111-117.

16. Camelier A, Rosa FW, Salim C, Nascimento OA, Cardoso F, Jardim JR. Using the Saint George's Respiratory Questionnaire to evaluate quality of life in patients with chronic obstructive pulmonary disease: validating a new version for use in Brazil. J Bras Pneumol 2006;32(2):114-122.

17. Pitta F, Probst VS, Kovelis D, Segretti NO, Mt Leoni A, Garrod R, Brunetto AF. Validation of the Portuguese version of the London Chest Activity of Daily Living Scale (LCADL) in chronic obstructive pulmonary disease patients. Rev Port Pneumol 2008;14(1):2747.

18. Jones PW, Quirk FH, Baveystock CM. The St George's Respiratory Questionnaire. Respir Med 1991;85(Suppl B):S25-S31; discussion 33-37.

19. Sousa TC, Jardim JR, Jones P. Validation of the Saint George's Respiratory Questionnaire in patients with chronic obstructive pulmonary disease in Brazil. J Pneumol 2000;26(3):119-128.

20. Iwama AM, Andrade GN, Shima P, Tanni SE, Godoy I, Dourado VZ. The six-minute walk test and body weight-walk distance product in healthy Brazilian subjects. Braz J Med Biol Res 2009;42(11): 1080-1085.

21. Ries AL. Minimally clinically important difference for the UCSD Shortness of Breath Questionnaire, Borg Scale, and Visual Analog Scale. COPD 2005;2(1):105-110.

22. Andrianopoulos V, Franssen FM, Peeters JP, Ubachs TJ, Bukari H, Groenen M, et al. Exercise-induced oxygen desaturation in COPD patients without resting hypoxemia. Respir Physiol Neurobiol 2014; 190:40-46.

23. Dal Corso S, Duarte SR, Neder JA, Malaguti C, de Fuccio MB, de Castro Pereira CA, Nery LE. A step test to assess exercise-related oxygen desaturation in interstitial lung disease. Eur Respir J 2007; 29(2):330-336.

24. Soguel Schenkel N, Burdet L, de Muralt B, Fitting JW. Oxygen saturation during daily activities in chronic obstructive pulmonary disease. Eur Respir J 1996;9(12):2584-2589.

25. Vogiatzis I, Zakynthinos S. Factors limiting exercise tolerance in chronic lung diseases. Compr Physiol 2012;2(3):1779-1817.

26. Velloso M, Stella SG, Cendon S, Silva AC, Jardim JR. Metabolic and ventilatory parameters of four activities of daily living accomplished with arms in COPD patients. Chest 2003;123(4):1047-1053.

27. Tangri S, Woolf CR. The breathing pattern in chronic obstructive lung disease during the performance of some common daily activities. Chest 1973;63(1):126-127.

28. Decramer M, De Benedetto F, Del Ponte A, Marinari S. Systemic effects of COPD. Respir Med 2005;99(Suppl 2):S3-S10.

29. Regueiro EM, Lorenzo VA, Parizotto AP, Negrini F, Sampaio LM. Analysis of metabolic and ventilatory demand during the execution of daily life activities in individuals with chronic obstructive pulmonary disease. Rev Lat Am Enfermagem 2006;14(1):41-47.

30. Lee L, Friesen M, Lambert IR, Loudon RG. Evaluation of dyspnea during physical and speech activities in patients with pulmonary diseases. Chest 1998;113(3):625-632.

31. Velloso M, Jardim JR. Study of energy expenditure during activities of daily living using and not using body position recommended by 


\section{Limitation of Activities of Daily Living AND COPD}

energy conservation techniques in patients with COPD. Chest 2006; 130(1):126-132.

32. Vaes AW, Wouters EF, Franssen FM, Uszko-Lencer NH, Stakenborg $\mathrm{KH}$, Westra $\mathrm{M}$, et al. Task-related oxygen uptake during domestic activities of daily life in patients with COPD and healthy elderly subjects. Chest 2011;140(4):970-979.

33. Mahler DA. Mechanisms and measurement of dyspnea in chronic obstructive pulmonary disease. Proc Am Thorac Soc 2006;3(3):234-238.

34. O'Donnell DE, Banzett RB, Carrieri-Kohlman V, Casaburi R, Davenport PW, Gandevia SC, et al. Pathophysiology of dyspnea in chronic obstructive pulmonary disease: a roundtable. Proc Am Thorac Soc 2007;4(2):145-168.

35. Rodriguez Gonzalez-Moro JM, de Lucas Ramos P, Izquierdo Alonso JL, López-Muñiz Ballesteros B, Antón Díaz E, Ribera X, Martín A.
Impact of COPD severity on physical disability and daily living activities: EDIP-EPOC I and EDIP-EPOC II studies. Int J Clin Pract 2009;63(5):742-750.

36. Jones PW, Brusselle G, Dal Negro RW, Ferrer M, Kardos P, Levy ML, et al. Health-related quality of life in patients by COPD severity within primary care in Europe. Respir Med 2011;105(1):57-66.

37. Antonelli-Incalzi R, Imperiale C, Bellia V, Catalano F, Scichilone N, Pistelli R, et al. Do GOLD stages of COPD severity really correspond to differences in health status? Eur Respir J 2003;22(3):444449.

38. Hsu KY, Lin JR, Lin MS, Chen W, Chen YJ, Yan YH. The modified Medical Research Council dyspnoea scale is a good indicator of health-related quality of life in patients with chronic obstructive pulmonary disease. Singapore Med J 2013;54(6):321-327. 